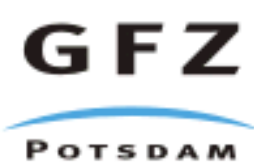

Originally published as:

Ivins, E. R., Wolf, D. (2008): Glacial isostatic adjustment: New developments from advanced observing systems and modeling. Review. - Journal of Geodynamics, 46, 3-5, 69-77

DOI: 10.1016/j.jog.2008.06.002. 


\title{
Glacial Isostatic Adjustment: New Developments from Advanced Observing Systems and Modeling
}

\author{
Erik R Ivins $^{\dagger}$ and Detlef Wolf ${ }^{\ddagger}$ \\ ${ }^{\dagger}$ Jet Propulsion Lab, California Institute of Technology, Pasadena, CA USA \\ ‡ GeoForschungZentrum Potsdam, Potsdam, Germany \\ and Institute of Geodesy, Stuttgart University, Stuttgart, Germany
}

\begin{abstract}
The measurement of glacial-isostatic adjustment (GIA) is one of the key ways in which geophysicists probe the long-term mantle rheology and Pleistocene ice history. GIA models are also tied to global and regional relative sea-level (RSL) histories, to $20^{\text {th }}$ century tide-gauge (TG) data and to space and terrestrial geodetic measurements. Two new types of observation are related to the high-resolution space-gravity data recovered from the Gravity and Climate Experiment (GRACE) satellite pair and the soon-to-be launched Gravity and Ocean Circulation Experiment (GOCE) with on-board threecomponent gradiometer. Gravity mapping has the unique capability of isolating those regions that lack isostatic equilibrium. When coupled with other space and terrestrial geodetic measurements, such as those of the Global Positioning System (GPS) networks and with multi-decade terrestrial gravity data, new constraints on GIA are in the offing and should soon illuminate new interpretations of ice-sheet history and mantle response. GIA studies also incorporate space-based altimetry data, which now provide multi-decadal coverage over continents, oceans and lakes. As we are approaching 72 monthly solutions of GRACE gravity coefficients for determining the Earth's secular component of gravity change over the continents, a new issue has surfaced: the problem of relying on interannual hydrological modeling to determine the hydrological contribution to the linear trend in the gravity field. Correctly extracting this contribution is germane to using the GIA-driven component for modeling solid-Earth and paleo-climatic parameters.
\end{abstract}

Seismic and heat-flux based models of the Earth's interior are emerging with ever higher levels of sophistication regarding material strength (or viscosity). A basic question raised is: how good are traditional Newtonian and non-Newtonian viscosity models that only allow radial variations of Earth parameters? In other words: under what 
circumstances must this assumption be abandoned for joint interpretations of new and traditional data sets. In this short review we summarize the issues raised in the papers forming this Special Issue (SI) dedicated to GIA.

\section{Introduction}

Mapping both the static and the time-varying Earth's gravity field as well as crustal uplift/subsidence patterns has long been known to be a key element for constraining glacial-isostatic adjustment (GIA) and, therefore, for providing critical data for constraining mantle viscosity on times scales of thousands to millions of years (e.g. O'Connell, 1971; Cathles, 1975; Kaula, 1978; Peltier, 1982). In this Special Issue (SI) of the Journal of Geodynamics eleven contributions are assembled that address the issue of time-varying gravity modeling, advanced 3-D numerical modeling and new combinations of altimetry, TG, GPS and GRACE data in order to determine more rigorously which models are compatible with the data for a variety of ice-sheet chronologies. The emphasis is on the solid-Earth and ocean responses to the former Laurentide and Fennoscandian ice sheets, as there is a wealth of relevant data coming from the North American GPS array and from the high-resolution BIFROST array in northern Europe. There is also great progress in integrating multi-decadal terrestrial gravity into new imaging of secular gravity derived from the GRACE mission since 2002. One of the functions of GIA models, within the broader field of environmental and paleoclimate sciences, is to provide the crustal motion and gravity changes, with error estimates, associated with the Earth's viscous memory of past ice-water loading (e.g. Mitrovica et al., 2008). This review is aimed at some of the issues under debate regarding how the uncertainty is estimated for the GIA models and where future modeling might find the most rewarding paths. The review is not intended to be comprehensive, but rather to provide some guidance and background for the topics of the SI.

\section{Terrestrial Observing Systems}

Absolute and relative gravity observations have been conducted in North America and Scandinavia (e.g. Ekman and Mäkinen, 1996; Lambert et al., 2001; Pagiatakis and 
Salib, 2003) for several decades. Such data sets are capable of detecting the secular increase in the geoid as mantle material returns to a gravitational quasi-equilibrium position that existed some 70 to 110 thousand years before present (kyr BP), at the beginning of the last glaciation. These data complement uplift and relative sea-level records and provide constraints on combinations of upper- and lower-mantle viscosity regimes (e.g. Wolf et al., 2006; Sella et al., 2007). Some constraints can also be placed upon the ice-sheet chronology from such data (e.g. Lambert et al., 2001; Tarasov and Peltier, 2004). The symbols of the relevant observables used here are $\Delta_{t} g, \Delta_{t} \mathcal{N}, \Delta_{t} w$, $h_{r s l}(t)$ and $\Delta_{t} h_{m s l}$ for time-rate of change in (surface) gravity, geoid, vertical crustal motion and relative height of mean sea-level indicated by paleo-shorelines (with age usually determined by radiometric dating) and TGs, respectively. Each of these can be interpreted as a geodetic quantity, with the exception of $h_{r s}(t)$, which is based on a variety of geomorphological or stratigraphic indicators of former sea level. The current accuracy of GPS-derived secular horizontal motion at the 1-mm/yr level means that GPS point positioning data may be used to determine the time-rate of change in (vector) horizontal crustal motion, $\Delta_{\mathrm{t}} \mathbf{u}$ (e.g. Lidberg et al., 2007). Throughout, the operator $\Delta_{\mathrm{t}}$ is employed to indicate either the modeled or the observed (based on a least-squares estimate) time derivative, albeit, for observing periods of less than a decade, these may be contaminated by interannual oscillations. Terrestrial systems capable of detecting GIA require a number of years of installation, and an important first step is to calibrate and register tidal and other environmental loading signals. Gravity is particularly sensitive to nearby changes in the cryosphere or hydrosphere and benefits from complementary vertical bedrock observation and, possibly, TG information (e.g. Sato et al., 2006). The registration of ocean and body tides is the subject of the paper by Sato et al. (2008). It describes a new observational system in Alaska whose goal is to provide data combinations that allow a better separation of crustal uplift and secular gravity variation due to present-day ice-mass changes from those due to Little Ice Age changes, as the latter dominate crustal uplift (Larsen et al., 2005). Since the Alaskan glacier demise is now a major contributor to global sea-level rise (about $0.25 \mathrm{~mm} / \mathrm{yr}$, Luthcke et al., 2008), there is a compelling rationale for installing such a system. Alaskan glacial loss was one of the first environmental observations inferred from the GRACE satellite mission (Tamisiea at el., 2005). Tidal signals recorded by gravimeters have peak-to- 
peak amplitudes of $150 \mu$ Gals $\left(1 \mathrm{Gal}=0.01 \mathrm{~m} / \mathrm{s}^{2}\right)$, while GIA-related trends are about two orders of magnitude smaller over one year.

Sato et al. (2008) also address the solid-Earth response to the ocean tidal load directly above the subducting Pacific plate. Motivated by the predictions of a finiteelement model (FEM) for elastic surface loading, Zürn et al. (1976) suggested that very accurate tidal recordings are especially sensitive to the higher rigidity of the slab. However, Sato et al. (2008) demonstrate that both the ocean tide and instrumental errors frustrate such discrimination.

Davis et al. (2008) work towards a better reconciliation of the north-south variability in $\Delta_{\mathrm{t}} \mathrm{h}_{\mathrm{msl}}$ along the United States east coast, as compiled in Permanent Mean Sea Level (PMSL) TG data. They use a self-gravitating FEM model for GIA with a 3-D viscosity distribution inferred from a seismic-velocity model. A potentially important feature is the ancient subduction of the Farralon Plate, some 80 million years ago, which has now penetrated into the top half of the lower mantle beneath the Atlantic (e.g. Bunge and Grand, 2000; see also Fig. 2 of Davis et al., 2008). The specific feature of the PMSL data along the eastern seaboard is that, from $37^{\circ}$ to $43^{\circ} \mathrm{N}$, the observed secular rate $\Delta_{\mathrm{t}} \mathrm{h}_{\mathrm{msl}}$ decreases from 4 to $1.5 \mathrm{~mm} / \mathrm{yr}$. Some of this variability can be explained by a combination of GIA forebulge collapse and self-gravitational effects, but other contributions, such as ocean thermosteric effects, are required to reconcile fully the misfit between prediction and observation. A key question is whether mantle models with more realistic lateral structures increase the predicted sea-level gradient, bringing it closer to the observed north-south trend. The required improvement is near the $1-\mathrm{mm} / \mathrm{yr}$ level.

Although no noticeable improvement in north-south trend results from the 3-D modeling effort, Davis et al. (2008) discover a model feature that is both ubiquitous and important. By differencing the predicted $\Delta_{\mathrm{t}} \mathrm{h}_{\mathrm{msl}}$ for 1-D and 3-D models (for equal radially averaged viscosities), respectively, they are able to show that, by using the seismologically constrained 3-D viscosity distribution, the predictions of GIA-corrected inferences of sea-level rise are smaller by about 0.5 to $0.7 \mathrm{~mm} / \mathrm{yr}$ (see Figure 4 of Davis et al., 2008). In other words, the GIA-predicted $\Delta_{\mathrm{t}} \mathrm{h}_{\mathrm{msl}}$ corrections are larger by this 
amount for 3-D viscosity models than for the equivalent 1-D models. The physical reason for this is the broader peripheral-bulge collapse that is predicted by the 3-D model, which contains the presumably colder Farralon plate beneath the eastern seaboard of the United States.

\section{Predictions and Constraints for 3-D Models}

While there is now a long history of predictions based on self-gravitating Maxwellviscoelastic 3-D Earth models, there has been relatively little success in developing models that definitively improve the fit of predictions to GIA data. However, advances in combining geologic, paleomagnetic and seismic data that constrain plate motions together with new global GPS reprocessing and reference-frame definition (e.g. Altamimi et al., 2007; Rülke et al., 2008) now offer new possibilities. Klemann et al. (2008) employ a spectral-FEM method (Martinec, 2000) for predicting horizontal and vertical GIA motions, using heat-flux and seismic data to quantify lateral variations of lithosphere thickness. The global model is fairly well-resolved, with spherical-harmonic truncation at $l_{\max }=156$, corresponding to a plate-boundary width of $200 \mathrm{~km}$. The upper mantle has a viscosity of $10^{21} \mathrm{~Pa}$ s and is assumed also to fill the volume of the plate-boundary zones. By decomposing the predicted motion into toroidal and poloidal components, Klemann et al. (2008) demonstrate that GIA velocity fields are equipartitioned in their predicted spherical-harmonic degree spectra above $l=5$, whereas all $1-D$ models predict purely spheroidal motions, analogous to modeling of mantle convection and plate tectonics (e.g. Becker, 2006). One result of this prediction is that GIA generates a measurable component of plate rotation, which is absorbed into the International Terrestrial Reference Frame (ITRF) global plate solutions, such as the recent ITRF2005 platemotion model (Altamimi et al., 2007) and into contemporary plate-mantle kinematicdynamic motion theories (e.g. Zandt and Humphreys, 2008).

The recent exploration of 3-D models has tempered the enthusiasm for being able to infer a high-resolution radial viscosity profile, and Paulson et al. (2007a) even suggested that GIA data are only able to resolve the horizontally averaged upper- and lower-mantle viscosities due to the uncertainty in the 3-D viscosity structure and the increased nonuniqueness of the model predictions. In contrast, other studies suggest that, where 
variability is controlled by independent information and ice-sheet configurations are well known, GIA data help constrain lateral variations in lithospheric strength (e.g. van den Berg et al., 2006). In this spirit, Wang et al. (2008) develop a strategy for retrieval of new constraints on the thermal contribution to the lateral viscosity structure of the mantle, using a 3-D self-gravitating Earth model for GIA predictions and a simple relation between seismic P-wave velocity and temperature as well as viscosity and temperature (Ivins and Sammis, 1995). Comparison of model predictions to observations of $\Delta_{\mathrm{t}} \mathrm{g}$, $\Delta_{\mathrm{t}} \mathrm{W}, \mathrm{h}_{\mathrm{rs}}(\mathrm{t})$ and $\Delta_{\mathrm{t}} \mathrm{u}$ suggests that the thermal contribution accounts for some 30 to $60 \%$ of the lateral heterogeneity. The strategy indicates that horizontal-motion data inferred from GPS experiments in Scandinavia provide the most promising constraints. The density of the Fennoscandian network is roughly one continuously operating station per $2700 \mathrm{~km}^{2}$, whereas the North American continuous network has less than half this density and, usually, less than half the total observation period (e.g. Henton et al., 2006; Lidberg, et al., 2007; Sella, et al., 2007).

\section{GRACE Space Gravity}

One of the fundamental questions in solid-Earth science is to determine what constitutive relationship governs the microscopic creep underlying both mantle convection and GIA (e.g. Karato and Wu, 1993). Having developed a long history of research in this area, Wu (2008) tests the assumption of power-law rheology with additional constraints coming from the GRACE data $\left(\Delta_{\mathrm{t}} \mathcal{N}\right)$, new GPS uplift data $\left(\Delta_{\mathrm{t}} \mathrm{w}\right)$, along with vertical motion inferred from relative sea-level histories $\left(h_{r s}(t)\right)$. In a previous study Wu (2001) concluded that a number of parameters of the non-linear constitutive law can be bounded by $h_{\mathrm{rs}}(t)$ data from the peripheral margins of ancient ice sheets, with the main upshot being that these data favor constitutive relations dominated by linearity. In his reassessment Wu (2008) now considers what properties of a particular ice-sheet history (ICE-4G, also see Peltier, 2004) must be altered in order to allow a larger degree of non-linearity in the rheology, as this is a feature favored by laboratory experiments and compatible with recent post-seismic deformation studies (e.g. Freed et al., 2006). All models with ICE-4G and non-linear rheology, however, fail to reach the magnitudes exhibited by GIA observables, including the new space-gravity data from GRACE. On the other hand, Wu (2008) finds that a model having power-law rheology restricted to the 
lower mantle correctly predicts the observations near the ice-sheet margins and along the peripheral bulges, with the proviso that the ICE-4G model is modified in two ways: the chronology must be younger by about $2 \mathrm{kyr}$ and the Laurentide ice sheet must be thicker by a factor of about 1.5 .

In Figures 1 and 2 the GRACE-observed (frames a) and predicted (frames b) GIA trends are portrayed as the surface water-layer thickness rate of change in $\mathrm{mm} / \mathrm{yr}$. Conversion factors from Stokes coefficients to equivalent water-layer thickness coefficients and the l-dependent Gauss smoothing radius are taken from Wahr et al. (1998) without elastic Love-number corrections. The predicted time-rate of change in Stokes coefficients are computed using the time-domain formulation for a self-gravitating Maxwell-viscoelastic layered sphere by Ivins et al. (1993) and the ICE-5G model. The viscosity structure assumed is $1-\mathrm{D}$. It is similar to the VM-2 model employed for constructing the ICE-5G model (Peltier, 2004) and also to the models used by Mitrovica and Forte (2004). What is remarkable about the GRACE results for northern North America and Scandinavia is how close the signals are to the predictions, in spite of a large hydrological interannual signal unremoved from the GRACE Level-2 product (Tapely et al., 2004). Paulson et al. (2007b) noted that positive hydrological trends extracted from the Global Land Data Assimilation (GDLAS) model of Rodell et al. (2004) in the region of the Laurentide ice sheet are only about one tenth of the total GRACE trend deduced from the CSR-04 (April 2002 to December 2006) coefficient set, each Gauss filtered with a $400-\mathrm{km}$ smoothing radius.

A major effort, however, was to remove the hydrological signal and to perform tests to ensure that signals from adjacent regions, such as from interannual ice-mass loss in Greenland, the Devon Ice Cap, southeastern Alaska, Svalbard etc., do not contaminate the recovery of a particular GIA signal (Tamisiea et al. 2007). This is the topic of three papers in the SI by Rangelova and Sideris (2008), van der Wal et al. (2008) and Steffen et al. (2008). Figures 1 and 2 show substantial mismatches between the GRACE signal (uncorrected for hydrology, frames a) and the model prediction for ICE-5G (frames b). The study by Tamisiea et al. (2007) also relied on surface-gravity measurements, an aspect of the modeling that is reinforced by the mentioned three studies. Although still lacking an appropriate portrayal of the Antarctic melt component (Ivins and James, 
2005) and less fine-tuned than the Australian National University model for Eurasia, the latest global ice model from the University of Toronto does treat North America in a greatly improved manner (Tarasov and Peltier, 2004) compared to ICE-4G. It features the thicker Laurentide ice at Last Glacial Maximum (LGM, 21 kyr BP), but does not have the 2 kyr younger chronology proposed by Wu (2008) in his study of power-law rheology. The ICE-5G model is expanded into spherical harmonics to $l_{\max }=\mathrm{m}_{\max }=256$ and the expansion is shown in Figure 3 at LGM as contours of relative ice thickness (with respect to present-day ice thickness). Note the very large ice thicknesses marked by the $5000-\mathrm{m}$ contours in North America. Eurasian ice at LGM, in contrast, has peak thicknesses at the 3000-m level (see the two small regions of blue color in Figure 3 in northern Europe). A prima facie observation is that both the average thicknesses at LGM and the GRACE trend magnitudes have a 4:1 ratio between Laurentia and Fennoscandia, consistent with the mass ratio of the ice sheets (Peltier, 2004). This indicates that, near the rebounding centers, the hydrological contribution is relatively mute, but near the periphery, where much of the model sensitivity exists (Davis et al., 2008; Wu, 2008), its satisfactory modeling is crucial.

In contrast to the study by Paulson et al. (2007b), the analysis by van der Wal et al. (2008) indicates that an increase in water mass occurs southwest of Hudson Bay from mid-2003 through mid-2006, having half the maximum of the GRACE-determined trend for 2002 to 2007. The hydrological trend is identified using a principal-component analysis, a technique well-known in atmosphere- and ocean-data analysis (e.g. Obukhov, 1947; Peixoto and Oort, 1992) and also employed in the analysis of Rangelova and Sideris (2008). In the study by van der Wal et al. (2008) it was necessary to employ three hydrological models and to determine overall optimum month-to-month consistency with the GRACE data. The optimum model for the period considered is the GDLAS model (Rodell et al., 2004), a result also obtained by Tamisiea et al. (2007). The application of the model for extracting the GIA signal is, nonetheless, problematic, since hydrological models are not expected to predict a truly secular signal. Thus, the extraction is dependent upon the sampling period. Interestingly, van der Wal et al. (2008) find a smaller misfit to the ICE-3G Laurentide ice-sheet history than to that of ICE-5G. The difference over North America between the two ice models at LGM is substantial, with the mass of the former about $22 \%$ smaller than that of the latter. 


\section{Combinations of Space and Terrestrial Gravity Data}

The study by Rangelova and Sideris (2008) places emphasis on putting GRACEderived rates of geoid change into an analysis framework identical with that of terrestrial time-independent gravity data (Lambert et al., 2001, 2006; Pagiatakis and Salib, 2003) and GPS-derived vertical-motion data (Henton et al., 2006). As a consequence, a leastsquares collocation method is applied to the combined data. However, as noted by Rangelova and Sideris (2008), the combination introduces uncertainty, which is probably larger than the uncertainty in the GLDAS hydrology model, due to the irregular temporal sampling of the gravity data and the short sampling period for the bulk of the GPS data. After recasting the combined data sets, a rotated principal-component and empirical orthogonal-function (PC/EOF) analysis is performed on a $1^{\circ} \times 1^{\circ}$ grid. The rotated PCs point to inadequacies in the hydrology models, as substantial annual signals emerge in the 'corrected' time series (see their Figure 5b). Of significance is that the rotated PC/EOF method may also provide a way to avoid leakage contamination caused by Alaskan and Greenland interannual ice-loss signals. The basic idea is that the orthogonality condition allows strong cryospheric seasonal and interannual behavior to be collected as a single eigenmode. Rangelova and Sideris (2008) conclude that the GRACE least-squares fit and the first rotated PC/EOF have common features when compared to the ICE-5G prediction. In particular, the peak GIA-model amplitude exceeds that of the combined data for either analysis type by about 25 to $39 \%$ at position $58^{\circ} \mathrm{N}$, $96^{\circ} \mathrm{W}$, just west of Hudson Bay, and both analyses show lobate structure in southeastern Hudson Bay (as in Figure 1 a). One possible implication is that errors in the hydrological model continue to be significant and that these undermine the search for GIA constraints using time-varying gravity data from GRACE. The reasons for the differences in the solutions found by a rotated PC/EOF method and the analyses of Tamisiea et al. (2007) and Paulson et al. (2007b) are not entirely clear. However, the choice of the PC/EOF analysis for deciphering the geophysical sources for the signal observed in the GRACE time-series clearly has a number of advantages (Schrama et al., 2007). 
Steffen et al. (2008) compare the predicted GIA gravity with the GRACE trend solutions for Fennoscandia, a study similar to that for the Laurentide postglacial relaxation. At least four features are different, however, two of which are obvious from Figures 1 to 3 : the smaller wavelength of the Fennoscandian rebound and its 1:4 reduction in observed and theoretical rates of change. Both differences imply a third difference: the promoted importance of a reliable linear trend in the hydrological models. A fourth difference is also quite fundamental: the relative abundance of data from terrestrial geodetic networks capable of constraining the magnitude and pattern of vertical motion in Fennoscandia (e.g. Ekman and Mäkinen, 1996; Milne et al., 2004; Mäkinen et al., 2006; Lidberg et al., 2007). The comparative robustness of the modeled network data imply that any GRACE-based GIA solution, once corrected for the hydrological trend, will have far fewer free fitting parameters, compared to North America, for inverse models that have appropriately integrated terrestrial geodetic data. Hence, flaws in the hydrological models or tidal de-aliasing products (e.g. Ray and Luthcke, 2006), atmosphere- and ocean-model imperfections or other correlated sampling errors (e.g. Bettadpur, 2007) should become readily apparent in solutions for GIA. Steffen et al. (2008) reveal substantial deficiencies of the hydrological models and, in particular, show that GRACE solutions using LaDWorld or WGHM disagree by more than $20 \%$. Also, neither model can explain the large positive secular change in mass inferred over Belarus and Ukraine (see Figure 2a). Table 1 summarizes GIA studies based on GRACE including those of the SI.

Time series from TG recordings in the Great Lakes may be compared to satellitealtimetry derived sea-surface height (SSH) time series. The latter are local sea-level data, while the former are referenced to the center of figure of the Earth. By differencing these altimetry data with local TG time series, point-wise vertical crustal motions may be inferred (e.g. Nerem and Mitchum, 2002). For the open ocean, SSH maps show decade-long trends and yield valuable information on global and regional sea-level change (e.g. Cummins et al., 2005). For densely monitored coastlines along the margin of large enclosed seas or lakes, such as the Black Sea, altimetry and TG combinations can be used to provide vertical crustal-motion data as well as their regional gradients (e.g. Garcia et al, 2007). When collocated with TG stations or at sites nearby, GPS vertical-displacement data allow the local rate solutions to be placed into a global 
geodetic framework. This provides an excellent source for precise GIA-related $\Delta_{\mathrm{t}} \mathrm{W}$ data in the Great Lakes region to further constrain GIA forward models. This is the main topic addressed in the paper by Braun et al. (2008) in the SI.

The number of stations that can be used in the study of GIA in the Great Lakes region is impressive. Braun et al. (2008) employ only subsets of the 55 TG and 70 GPS sites available, utilizing optimized tide-gauge/altimetry (TG/ALT) combinations (see their Figures 2 and 3). The TG/ALT and stand-alone GPS data are compared to predictions of 70 GIA models by combining three ice-load histories (ICE-3G, 4G \& 5G) with a broad range of $1-D$ and $3-D$ viscosity models. The Great Lakes data are from the transition zone between present-day uplift and subsidence at the southern margin of the LGM Laurentide ice sheet. The authors show that the data are best satisfied using the ICE$3 G$ model, a fact that should be considered when designing the next generation of icesheet models.

\section{Combinations of GOCE with Altimetry and Space-Gravity Data: The Future}

Information on the viscosity of the shallow upper mantle is highly dependent upon the tectonic province considered. To date, no spatially comprehensive data set has been collected that constrains mantle viscosity in the shallow mantle, above the $410-\mathrm{km}$ seismic discontinuity, on a continental scale. Only for Fennoscandia do current 1-D models come close to realizing such a broad-scale constraint on the viscosity above 410-km depth (e.g. Milne et al., 2001). However, petrological (e.g. Wood, 1995), rockmechanical (e.g. Karato, 1997) and seismic-imaging data showing slabs entrained in flow just above the 660-km discontinuity (e.g. Huang and Zhao, 2006) independently indicate that the upper mantle is rheologically stratified down to the $410-\mathrm{km}$ discontinuity. The rheology of the lower continental crust is also under debate (e.g. Klemann and Wolf, 1999). Understanding the strength contrast between the lower crust and the peridotites (that lie at the base of the crust) remains one of the fundamental problems in continental tectonophysics (e.g. Afonso and Ranalli, 2004). 
In the SI Vermeersen and Schotman (2008) suggest that the high resolution of the GOCE gravity mission is accompanied by enhanced sensitivity to the details of the viscous stratification in the top $400 \mathrm{~km}$ of the mantle and in the continental crust. The key is to map the static geoid near the margins of the ancient Laurentide and Fennoscandian ice sheets to spherical-harmonic degree and order 150. Features that have geoidundulation wavelengths of $200 \mathrm{~km}$ could then be well resolved during the 18-month GOCE mission. Vermeersen and Schotman (2008) compute forward models showing that a detectable geoid perturbation of 0.25 to $1 \mathrm{~m}$ can be induced by a thin sandwich layer of very low viscosity within and below the elastic lithosphere. However, geophysical filters must be assembled that remove other static geoid signatures, including those associated with ocean circulation or of solid-Earth origin, such as sedimentary and petrologic lateral variability. After such filtering, the GOCE mission could provide new constraints on the creep strength and, ultimately, better illuminate the physics and chemistry of the Earth's lower crust and shallow mantle on a continental scale. GIA models that use both GOCE-determined static and GRACE-determined time-varying fields in concert with crustal-motion data could tighten the bounds on the viscosity structure above the $410-\mathrm{km}$ discontinuity.

An advantage of GRACE observations over terrestrial data is the excellent long wavelength coverage of the former. This wide field of view offers certain advantages despite the high-degree and -order stripping related to sampling (Bettadpur, 2007)., Radar and lidar mapping potentially have similar capabilities in terms of coverage and, indeed, have been very effectively used for studying surface changes of ice sheets, oceans, lakes and sea ice.

The Ku-band 10-Hz radar-mapping instrument onboard the TOPEX/POSEIDON (T/P) satellite has a demonstrated wide-swath capability with an along-track resolution of 0.6 km. Having developed a novel retracking algorithm that exploits the 10-Hz/64-sample waveforms and applying this to 355 consecutive 10-day orbit cycles of the T/P mission, Lee et al. (2008) stack this vertical-height information with respect to the C-band SRTM DEM (16-m absolute error and 6-m relative error) on a reference ellipsoid with geoid undulations on a 360-degree and -order representation of the EGM-96 gravity model. The stacked retracking algorithm is capable of detecting height changes provided that 
subsets of the orbit cycles are highly repeatable. Lee et al. (2008) demonstrate the feasibility of this for the south coast of Hudson Bay, where the standard deviation of retracked satellite-to-surface heights is $2 \mathrm{~m}$ or less. The algorithm must be accurately corrected for tropospheric- and ionospheric-path delays. For these, the European Center for Medium Range Weather Forecasting (ECMWF) model and direct DORIS data, respectively, were employed. Surface-gradient corrections must also be applied to the SRTM DEM model.

An advantage of the T/P satellite is the length of its period of continuous operation: 1992 to 2003. Furthermore, global height-change detection is achieved at a 4-mm/yr accuracy level (see Figure 5 of Lee et al., 2008). In the paper by Lee et al. (2008) a spatially comprehensive sub-decimeter-level multi-year mapping procedure is carried out just south of Hudson Bay, with formal uncertainties ranging from 2.5 to $5.0 \mathrm{~mm} / \mathrm{yr}$, and integrated into GRACE-, TG-, altimetry- or GPS-inferred vertical motion in order to obtain a uniform data set near the southern margin of the ancient Laurentide ice sheet. This offers the complementary employment of two spatially and temporally turgescent techniques, altimetric and space-gravity mappings, for determining GIA patterns and magnitudes in the future. Wu et al. (2002) analyzed the simultaneous measurement of the GIA signal in Canada by ICESat (Ice, Cloud, and land Elevation Satellite) and by GRACE and concluded that joint inversions of the data sets might be capable of determining the Laurentide ice-sheet thickness with errors of less than 300 to $400 \mathrm{~m}$ at LGM. Clearly, the full exploitation of such data combinations holds promise in formulating strategies for the next generation of advanced GIA observing systems.

\section{Summary}

The last decade has witnessed important advancements in the resolution and accuracy of forward modeling of GIA using 3-D viscosity structures (e.g. Davis et al., 2008; Klemann et al., 2008; Wang and Wu, 2008) and the consideration of more realistic non-linear rheologies (e.g. Wu, 2008). During the past five years, however, the most pronounced advances in understanding GIA have been derived from the advanced observing systems onboard ongoing satellite missions (e.g. CHAMP, GRACE) and, more 
recently, from progress in realizing a geodetically stable reference frame (ITRF2005), from which GPS observations (e.g. Klemann et al., 2008; Rülke et al., 2008), a variety of T/P-altimetry, TG, terrestrial-gravity and GPS data combinations take advantage (e.g. Braun et al., 2008; Lee et al., 2008; Sato et al., 2008). Comprehensive time-dependent gravity mapping using GRACE (e.g. Rangelova and Sideris, 2008; Steffen et al., 2008; van der Wal et al., 2008) now offer an eight-year-long time series, from which unprecedented improvements in understanding GIA will emerge provided that advances are simultaneously achieved in interannual hydrology modeling. The GOCE mission, slated for a mid-2008 launch, is expected to provide valuable high-resolution mapping of the static geoid. This mapping will further an understanding of the mode of GIA in the shallow upper mantle and lithosphere (e.g. Vermeersen and Schotman, 2008) and advance an understanding of the size and collapse history of the ancient ice sheets in Arctic Canada and in the northern parts of Fennoscandia and the Barents Sea.

\section{Acknowledgements}

The work of E.I. was performed at the Jet Propulsion Laboratory, Caltech, and funded by the Solid Earth and Surface Processes Focus Area for GRACE Science within NASA's Earth Science Program. The work of D.W. is related priority program SPP 1257 Mass Transport and Mass Distribution in the Earth System funded by the German Research Foundation (DFG). The Editor in Chief of the J. Geodynamics, Randell Stephenson, is thanked for a review of the manuscript. 


\section{References}

Afonso, J.C., Ranalli, G., (2004). Crustal and mantle strengths in continental lithosphere: Is the jelly sandwich model obsolete? Tectonophyisics, 394, 221-232.

Altamimi, Z., X. Collilieux, J. Legrand, B. Garayt, and C. Boucher, (2007) ITRF2005: A new release of the International Terrestrial Reference Frame based on time series of station positions and Earth Orientation Parameters, J. Geophys. Res., 112, B09401, doi:10.1029/2007JB004949.

Cathles, L.M., (1975) The Viscosity of the Earth's Mantle, Princeton University Press, Princeton, N.J., pp. 386.

Cummins, P.F., G.S.E. Lagerloef and G. Mitchum (2005). A regional index of northeast Pacific variability based on satellite altimeter data, Geophys. Res. Lett., 32, L17607, doi:

10.1029/2005GL023642

Becker, T.W., (2006). On the effect of temperature and strain-rate dependent viscosity on global mantle flow, net rotation, and plate-driving forces, Geophys. J. Int., 167, 943-957

doi:10.1111/j.1365-246X.2006.03172.x.

Bettadpur, S. (2007). Separability and aliasing: a GRACE focused discussion, Workshop on the Future of Satellite Gravimetry, April 12, 2007, ESTEC, Noordwijk, The Netherlands.

Braun, A., C-Y. Kuo, C.K. Shum, P. Wu Patrick, W. van der Wal and G. Fotopoulos, (2008). Glacial isostatic adjustment at the Laurentide ice sheet margin: Models and Observations in the Great Lakes region, J. Geodynamics, this issue.

Bunge, H-P. and S. P. Grand, (2000). Mesozoic plate-motion history below the northeast Pacific Ocean from seismic images of the subducted Farallon slab, Nature, 405, 337-340, doi:10.1038/35012586.

Davis, J.E., K. Latychev, J.X. Mitrovica, R. Kendall and M. E. Tamisiea, (2008). Glacial isostatic adjustment in 3-D earth models: implications fro the analysis of tide gauge records along the U.S. east coast, J. Geodynamics, this issue.

Ekman M. and J. Mäkinen, (1996). Recent postglacial rebound, gravity change and mantle flow in Fennoscandia, Geophy. J Int., 126, 229-234.

Freed, A.M., Bürgmann, R., Calais , E., and J. Freymueller (2006). Stress-dependent power-law flow in the upper mantle following the 2002 Denali, Alaska, earthquake, Earth and Planet. Sci. Lett., 252, 481-489.

Garcia, D., I. Vigo, B.F. Chao and M.C. Martinez (2007). Vertical crustal motion along the Mediterranean and Black Sea coast derived from ocean altimetry and tide gauge data, Pure and Applied Geophys., 164, 851-863.

Han, S-C., C.K. Shum, C. Jekeli, C-Y. Kuo, C.R. Wilson and K-W. Seo, (2005). Non-isotropic filtering of GRACE temporal gravity for geophysical signal enhancement, Geophys. J. Int., 163, 18-25.

Henton, J.A., M.R. Craymer, R. Ferland, H. Dragert, S. Mazzotti and D. Forbes, (2006). Crustal 
motion and deformation monitoring of the Canadian landmass. Geomatica, 60, 173-191.

Huang, J., and D. Zhao (2006). High-resolution mantle tomography of China and surrounding regions, J. Geophys. Res., 111, B09305, doi:10.1029/2005JB004066.

Ivins, E.R., C.G. Sammis and C. F. Yoder (1993). Deep mantle viscous structure with prior estimate and satellite constraint, J. Geophys. Res., 98, 4579-4609.

Ivins, E.R. and C.G. Sammis, (1995). On lateral viscosity in the mantle and the rheology of low frequency geodynamics, Geophysical J. Int., 123, 305-322.

Ivins, E.R. and T.S. James, (2005). Antarctic glacial isostatic adjustment: A new assessment, Antarctic Science, 17, 537-549.

Karato, S. and P. Wu (1993). Rheology of the upper mantle: a synthesis, Science, 260, 771-778.

Karato, S. (1997). Phase transformations and rheological properties of mantle minerals, in Earth's Deep Interior: The Doornbos Memorial Volume, (ed. D. J. Crossley) Gordon and Breach Sci., Amsterdam, 223-272.

Kaula, W.M., (1978). Geodynamic problems, in Applications of Geodesy to Geodynamics, Rep. Dept of Geodetic Science, \# 280, (ed., I.I. Mueller), 345-351.

Klemann, V., Z. Martinec, E.R. Ivins, (2008). Glacial isostasy and plate motion, J. Geodynamics, this issue.

Klemann, V. and D. Wolf (1999). Implications of a ductile crustal layer for the deformation caused by the Fennoscandian ice sheet, Geophys. J. Int., 139, 216-226.

Lambert, A., N. Courtier, G.S. Sasagawa, F. Klopping, D. Winester, T.S. James and J.O. Laird, (2001). New constraints on Laurentide postglacial rebound from absolute gravity measurements, Geophys. Res. Lett., 28, 2109-2112.

Lambert, A., N. Courtier and T.S. James (2006). Long-term monitoring by absolute gravimetry: Tides to postglacial rebound. J. Geodynamics, 41, 307-317.

Larsen, C.F., Motyka, R.J., Freymueller, J.T., Echelmeyer, K.A. and Ivins, E.R., (2005) Rapid viscoelastic uplift in southeast Alaska caused by post-Little Ice Age glacial retreat. Earth and Planet. Sci. Lett., 237, 548-560.

Lee, H., C. K. Shum, Y. Yi, A. Braun and C-Y. Kuo, (2008). Laurentia crustal uplift observed using satellite radar altimetry, J. Geodynamics, this issue.

Lidberg, M., J. M. Johansson, H.-G. Scherneck and J. L. Davis, (2007). An improved and extended GPS-derived 3D velocity field of the glacial isostatic adjustment (GIA) in Fennoscandia, J. Geodesy, 81, 213-230.

Luthcke. S., A.A. Arndt, D.D. Rowlands, J.J. McCarthy and C.F. Larsen, (2008). Recent glacier mass changes in the Gulf of Alaska region from GRACE mascon solutions, J. Glaciology, in press.

Mäkinen, J., H. Koivula, M. Poutanen and V. Saaranen, (2003). Vertical velocities in Finland from permanent GPS networks and from repeated precise leveling, J. Geodynamics, 35, 443-456. 
Martinec, Z., (2000). Spectral-finite element approach for three-dimensional viscoelastic relaxation in a spherical earth. Geophys. J. Int., 142, 117-141.

Milne, G.A., Mitrovica, J.X., Scherneck, H-G., Davis, J.L., Johansson, J.M., Koivula, H. and M. Vermeer (2004). Continuous GPS measurements of postglacial adjustment in Fennoscandia: 2. Modeling results. J. Geophys. Res., Vol. 109, B02412, doi:10.1029/2003JB002619,

Mitrovica, J.X. and A.M. Forte, (2004). A new inference of mantle viscosity based upon joint inversion of convection and glacial isostatic adjustment data. Earth Planet. Sci. Lett., 225, 177189.

Mitrovica, J.X., M.E. Tamisiea, E.R. Ivins, L.L.A. Vermeersen, G.A. Milne and K. Lambeck, (2008). Surface mass loading on a dynamic earth: Complexity and contamination in the analysis of global sea level trends, In Understanding Sea-level Rise and Variability, A Chapter for a World Climate Research Programme, Cambridge University Press, in press.

Nerem R.S. and G.T. Mitchum, (2002). Estimates of vertical crustal motion derived from differences of TOPEX/POSEIDON and tide gauge sea level measurements, Geophys. Res. Lett., (19) L1934.

Obukhov, A.M. (1947). Statistically homogeneous fields on a sphere. Usp. Mat. Nauk, 2, 196-198.

O'Connell, R.J. (1971). Pleistocene glaciation and the viscosity of the lower mantle, Geophys. J. Int., 23, 299-327, doi:10.1111/j.1365-246X.1971.tb01823.x.

Pagiatakis, S.D. and Salib, P. (2003). Historical relative gravity observations and the time rate of change of gravity due to postglacial rebound and other tectonic movements in Canada, $\mathrm{J}$. Geophys. Res., 108, B2406, doi:10.1029/2001JB001676.

Paulson, A. Zhong, S. and Wahr, J. (2007a) Limitations on the inversion for mantle viscosity from postglacial rebound, Geophys. J. Int., 168, 1195-1209.

Paulson, A., Zhong, S. and J. Wahr (2007b) Inference of mantle viscosity from GRACE and relative sea level data, Geophys. J. Int. 171, 497-508, doi:10.1111/j.1365-246X.2007.03556.x.

Peixoto, J.P. and A.H. Oort, (1992) Physics of Climate, Springer, New York, pp. 520.

Peltier, W.R., (1982) Dynamics of the Ice Age Earth, Advances in Geophysics, 24, 1-146.

Peltier, W.R., (2004) Global glacial isostasy and the surface of the ice-age Earth: The ICE-5G (VM2) model and GRACE Ann Rev. Earth and Planet. Sci., 32, 111-149.

Rangelova, E. and M.G. Sideris, (2008), Contributions of terrestrial and GRACE data to the study of the secular geoid changes in North America, J. Geodynamics, this issue.

Ray, R.D. and S.B. Luthcke (2006). Tide model errors and GRACE gravimetry: towards a more realistic assessment, Geophys. J. Int., 167, 1055-1059.

Rodell, M., Houser, P.R., Jambor ,U., Gottschalck, J., Mitchell, K., Meng, C.-J., Arsenault, K., Cosgrove, B., Radakovich, J., Bosilovich, M., Entin, J. K., Walker, J. P., Lohmann, D. and Toll, D., (2004). The global land data assimilation system, Bull. Am. Meteorol. Soc., 85, 381-394. 
Rülke, A., R. Dietrich, M. Fritsche, M. Rothacher and P. Steigenberger (2008). Realization of the Terrestrial Reference System by a reprocessed global GPS network, J. Geophys. Res., 112, B---, doi:10.1029/2007JB005231.

Sato T., J. Okuno, J. Hinderer, D.S. MacMillan, H-P. Plag, O. Francis, R. Falk and Y. Fukuda, (2006) A geophysical interpretation of the secular displacement and gravity rates observed at Ny-Alesund, Svalbard in the Arctic: Effects of the post-glacial rebound and present-day ice melting, Geophys. J. Int, 165, 729-743

Sato, T., S. Miura, Y. Ohta, H. Fujimoto, W. Sun, C.F. Larsen, M. Heavner, A.M. Kaufman and J.T. Freymueller, (2008). Earth tides observed by gravity and GPS in southeastern Alaska, J. Geodynamics, this issue.

Schrama, E. J. O., B. Wouters, and D. A. Lavallée (2007). Signal and noise in Gravity Recovery and Climate Experiment (GRACE) observed surface mass variations, J. Geophys. Res., 112, B08407, doi:10.1029/2006JB004882.

Sella, G.F., S. Stein, T. H. Dixon, M. Craymer, T. S. James, S. Mazzotti and R. K. Dokka (2007). Observation of glacial isostatic adjustment in "stable" North America with GPS, Geophys. Res. Lett., 34, L02306, doi:10.1029/2006GL027081.

Steffen, H., H. Denker and J. Mueller, (2008). Glacial isostatic adjustment in Fennoscandia from GRACE data and comparison with geodynamical models, J. Geodynamics, this issue.

Swenson, S. and J. Wahr (2006). Post-processing removal of correlated errors in GRACE data, Geophys. Res. Lett., 33, L08402, doi:10.1029/2005GL025285.

Tamisiea, M. E., E. Leuliette, J.L. Davis and J.X. Mitrovica, (2005). Constraining hydrological and cryospheric mass flux in southeastern Alaska using space-based gravity measurements, Geophys. Res. Lett., 32, L20501, doi:10.1029/2005GL023961.

Tamisiea, M.E., J.X. Mitrovica and J.L. Davis, (2007). GRACE gravity data constrain ancient ice geometries and continental dynamics over Laurentia, Science, 316, 881-883.

Tapley, B.D., S. Bettadpur, J.C. Ries, P.F. Thompson and M.M. Watkins, (2004). GRACE measurements of mass variability in the Earth system, Science, 305, 503-505.

Tarasov, L. and W.R. Peltier, (2004). A geophysically constrained large ensemble analysis of the deglacial history of the North American ice-sheet complex, Quaternary Sci. Rev., 23, 359-388.

van den Berg, J., R.S.W.V. de Wal and J. Oerlemans (2006). Recovering lateral variations in lithospheric strength from bedrock motion data using a coupled ice sheet-lithosphere model, $J$. Geophys. Res., 111, B05409, doi:10.1029/2005JB003790

van der Wal, W., P. Wu, M.G. Sideris and C.K. Shum, (2008). Use of GRACE-determined secular gravity rates for glacial isostatic adjustment studies in North America, J. Geodynamics, this issue.

Vermeersen, B.L.A. and H.H. Schotman, (2008). High-harmonic geoid signatures related to glacial isostatic adjustment and their detectability by GOCE, J. Geodynamics, this issue. 
Wahr, J., M. Molenaar, and F. Bryan (1998). Time variability of the Earth's gravity field: Hydrological and oceanic effects and their possible detection using GRACE, J. Geophys. Res., $103,30,205--30,230$.

Wang, H. P. Wu and W. van der Wal, (2008). On the possibility of using GIA observables to constrain the thermal contribution to lateral variations in mantle viscosity, J. Geodynamics, this issue.

Wolf, D., V. Klemann, J. Wunsch and F.P. Zhang (2006). A reanalysis and reinterpretation of geodetic and geological evidence of glacial-isostatic adjustment in the Churchill region, Hudson Bay, Surveys Geophys., 27, 19-61.

Wood, B.J., (1995). The effect of $\mathrm{H}_{2} \mathrm{O}$ on the 410-kilometer seismic discontinuity, Science, 268, 74-76, doi: 10.1126/science.268.5207.74

Wu, P., (2001). Postglacial induced surface motion and gravity in Laurentia for uniform mantle with power-law rheology and ambient tectonic stress, Earth \& Planet. Sci. Lett., 186, 427-435.

Wu, P. (2008). Postglacial isostatic adjustment in a self-gravitating spherical earth with power-law rheology, J. Geodynamics, this issue.

Wu, X., M. M. Watkins, E. R. Ivins, R. Kwok, P. Wang, and J. M. Wahr (2002), Toward global inverse solutions for current and past ice mass variations: Contribution of secular satellite gravity and topography change measurements, J. Geophys. Res., 107, B2291, doi:10.1029/2001JB000543.

Zandt, G. and E. Humphreys (2008). Toroidal mantle flow through the western U.S. slab window, Geology, 36, 295-298, doi: 10.1130/G24611A.1.

Zürn, W., Beaumont, C., and Slichter, L. B., (1976). Gravity tides and ocean loading in southern Alaska, J. Geophys. Res., 81, 4923-4932. 


\section{Figure Captions}

Figure 1. (a) Laurentian GRACE-derived water-equivalent mass changes and (b) ICE$5 \mathrm{G}$ model prediction for a lowermost lower-mantle viscosity of $4 \times 10^{21} \mathrm{~Pa} \mathrm{~s}$, an uppermost lower-mantle viscosity of $1.9 \times 10^{21} \mathrm{~Pa} \mathrm{~s}$, an upper-mantle viscosity of $5 \mathrm{x}$ $10^{20} \mathrm{~Pa} \mathrm{~s}$ and a lithosphere thickness of $100 \mathrm{~km}$. The GRACE signal is unfiltered by hydrological modeling. The GRACE Level 2 product employed is from Release 01 of the Center for Space Sciences (CSR), which uses the months January 2003 to December 2006, excluding July 2003. The harmonics are truncated at degree and order 60 and a Gauss filter of $575-\mathrm{km}$ radius is applied.

Figure 2. (a) Fennoscandian GRACE-derived water-equivalent mass changes and (b) ICE-5G model prediction for the viscosity model used in Figure 1 and without hydrological modeling. Since the emergence of a clear rebound signal requires a longer period of GRACE observation than in Figure 1, Release 04 of CSR is employed, which uses the months January 2003 to December 2006, excluding July 2003. The spherical harmonics are truncated at degree and order 60 and a Gauss filter of $575-\mathrm{km}$ radius without destriping is applied.

Figure 3. Northern hemispheric ICE-5G ice sheet model at LGM. Ice sheets are resolved in a spherical harmonic expansion of the differential ice thickness in meters with respect to today's thickness (on a rigid Earth and without the ocean load deficit) to degree and order 256. 
Table 1. GRACE studies of GIA in North America and Fennoscandia (S2008).

\begin{tabular}{|c|c|c|c|c|c|}
\hline Study & T2007 & P2007 & W2008 & R2008 & S2008 \\
\hline $\begin{array}{l}\mathrm{SH} \\
\text { release }\end{array}$ & $\begin{array}{l}\text { CSR R01 (04/02 to } \\
04 / 06)\end{array}$ & $\begin{array}{l}\text { CSR R04 } \\
(04 / 02 \text { to } 12 / 06)\end{array}$ & $\begin{array}{l}\text { CSR R04 }(08 / 02 \\
\text { to } 07 / 07)\end{array}$ & $\begin{array}{l}\text { CSR R01 (04/02 to } \\
03 / 06)\end{array}$ & $\begin{array}{l}\text { CSR R04 (04/02 to 05/07), JPL R04 } \\
\text { (01/03 to 04/07), GFZ R04 (08/02 to } \\
\text { 03/07) }\end{array}$ \\
\hline $\begin{array}{l}\text { ice } \\
\text { model }\end{array}$ & ICE-5G ${ }^{\ddagger}$ & ICE-5G ${ }^{\ddagger}$ & ICE-3G & ICE-5G & RSES (ANU) \\
\hline $\begin{array}{l}\text { hydro. } \\
\text { model }\end{array}$ & GDLAS & GDLAS & GDLAS + LaD ${ }^{\dagger}$ & GDLAS & WGHM, LaDWorld \\
\hline filtering & $\begin{array}{l}\mathrm{R}_{\mathrm{l}}=500 \mathrm{~km}, \mathrm{SW} 06 \\
\text { destripping }\end{array}$ & $\begin{array}{l}\mathrm{R}_{\mathrm{I}}=400 \mathrm{~km} \\
\text { SW06 } \\
\text { destripping }\end{array}$ & $\begin{array}{l}\mathrm{R}_{\mathrm{I}}=500 \mathrm{~km}, \\
\text { SW06 } \\
\text { 'optimized' } \\
\text { signal-to-noise } \\
\text { destripping }\end{array}$ & $\begin{array}{l}\mathrm{R}_{\mathrm{l}}=400 \mathrm{~km} \\
\text { wavelet smoothing }\end{array}$ & $\begin{aligned} \text { i. } & \mathrm{R}_{\mathrm{l}}=400 \mathrm{~km} \text { (alone), } \\
\text { ii. } & \text { non-isotropic, Han et al. } \\
& (2005), \\
\text { iii. } & \text { identical to } \mathrm{P} 2007^{\ddagger \ddagger}\end{aligned}$ \\
\hline $\begin{array}{l}\text { trend } \\
\text { estimate }\end{array}$ & least squares & least squares & PC/EOF & rotated PC/EOF & ellipsoidal pattern-matching algorithm \\
\hline notes & $\begin{array}{l}25-45 \% \text { static } \\
\text { free-air gravity } \\
\text { due to GIA is } \\
\text { explained } \\
\text { double-dome } \\
\text { ice model } \\
\text { identified } \\
2.5 \times 10^{21} \leq \eta_{\mathrm{LM}} \\
\leq 4.0 \times 10^{21}, 3.0 \\
\times 10^{20} \leq \eta_{\mathrm{UM}} \leq \\
1.0 \times 10^{21} \mathrm{~Pa} \text { S }\end{array}$ & $\begin{array}{ll}\text { - } & \mathrm{h}_{\mathrm{rsl}}(\mathrm{t}) \text { near } \\
\text { Hudson } \\
\text { Bay } \\
\text { employed } \\
\mathrm{H}_{2} \mathrm{O} \text { mass } \\
\leq 10 \% \text { of } \\
\text { GRACE } \\
\text { trend } \\
\eta_{\mathrm{LM}} \approx 2.3 \\
\mathrm{x} 10^{21}, \eta_{\mathrm{UM}} \\
\approx 5.3 \mathrm{x} \\
10^{20} \mathrm{~Pa} \mathrm{~s}\end{array}$ & $\begin{array}{ll}\text { - } & \text { error } \\
\text { estimates in } \\
\mathrm{GIA} \text { and } \\
\mathrm{H}_{2} \mathrm{O} \\
\text { storage } \\
\mathrm{H}_{2} \mathrm{O} \text { - mass } \\
\text { discrepancy } \\
\text { about } 10 \% \\
\text { of GRACE } \\
\text { trend signal }\end{array}$ & $\begin{array}{ll}\text { - } & \Delta_{\mathrm{t}} \mathrm{g}, \Delta_{\mathrm{t}} \mathrm{w} \text { data } \\
\text { employed } \\
\text { - } \quad \text { non-secular } \\
\text { residual EOFs } \\
\text { indicate } \\
\text { inadequacy of } \\
\text { 'best' } \\
\text { hydrology } \\
\text { model } \\
\text { (GDLAS) } \\
\text { ICE-5G(VM2) } \\
\text { overestimates } \\
\text { GRACE \& } \\
\text { terrestrial } \\
\text { combination } \\
\text { by } 25 \text { to } 39 \%\end{array}$ & $\begin{array}{l}\text { - } \quad \mathrm{h}_{\mathrm{rss}}(\mathrm{t}) \text { of Fennoscandia employed } \\
\mathrm{GIA} \text { maximum magnitudes } \\
\text { discrepant at } 20 \% \text { level due } \\
\text { differences in releases } \\
\text { disparities in the hydrological } \\
\text { models yield even larger solution } \\
\text { differences } \\
\text { position of central rebound is } \\
\text { consistent with GRACE as is } \\
\text { magnitude }(1.33 \mu \mathrm{Gal} / \mathrm{yr})\end{array}$ \\
\hline
\end{tabular}

${ }^{\ddagger}$ Strongly preferred, ${ }^{\ddagger}$ Weakly preferred, ${ }^{\dagger}$ Used for a priori error estimate. (T2007 = Tamisiea et al., 2007; P2007 = Paulson et al., 2007; W2008 = van der Wal et al. 2008; R2008 = Rangelova and Sideris, 2008; S2008 = Steffen et al., 2008). 
575km Gaussian Smoothing - water equivalent

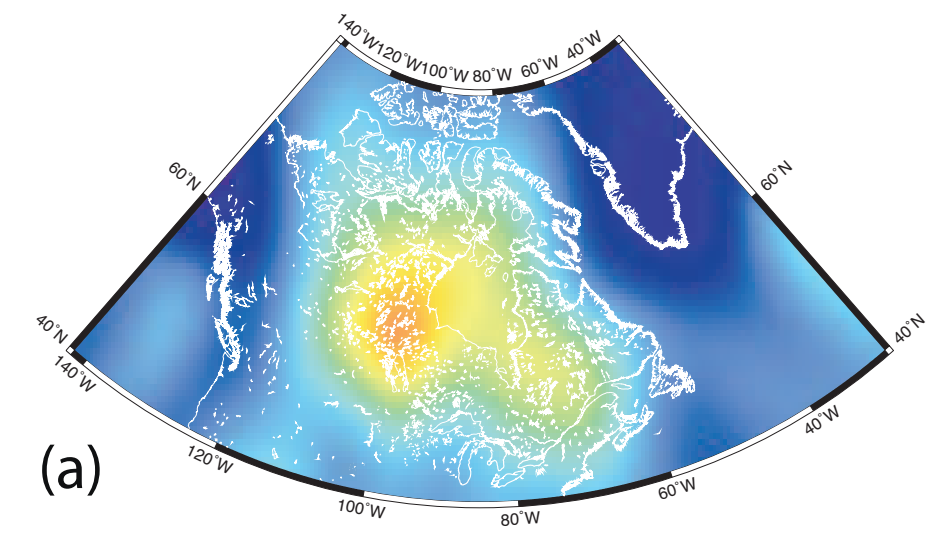

Trend in GRACE for CSR_RL01
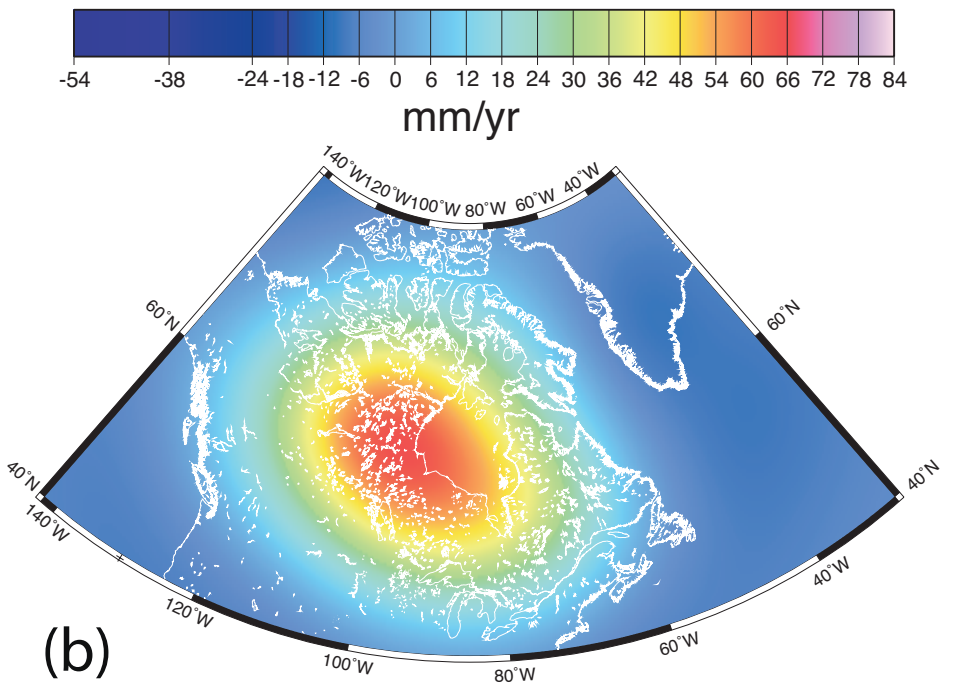

Trend predicted by GIA (ICE-5G MF05) 


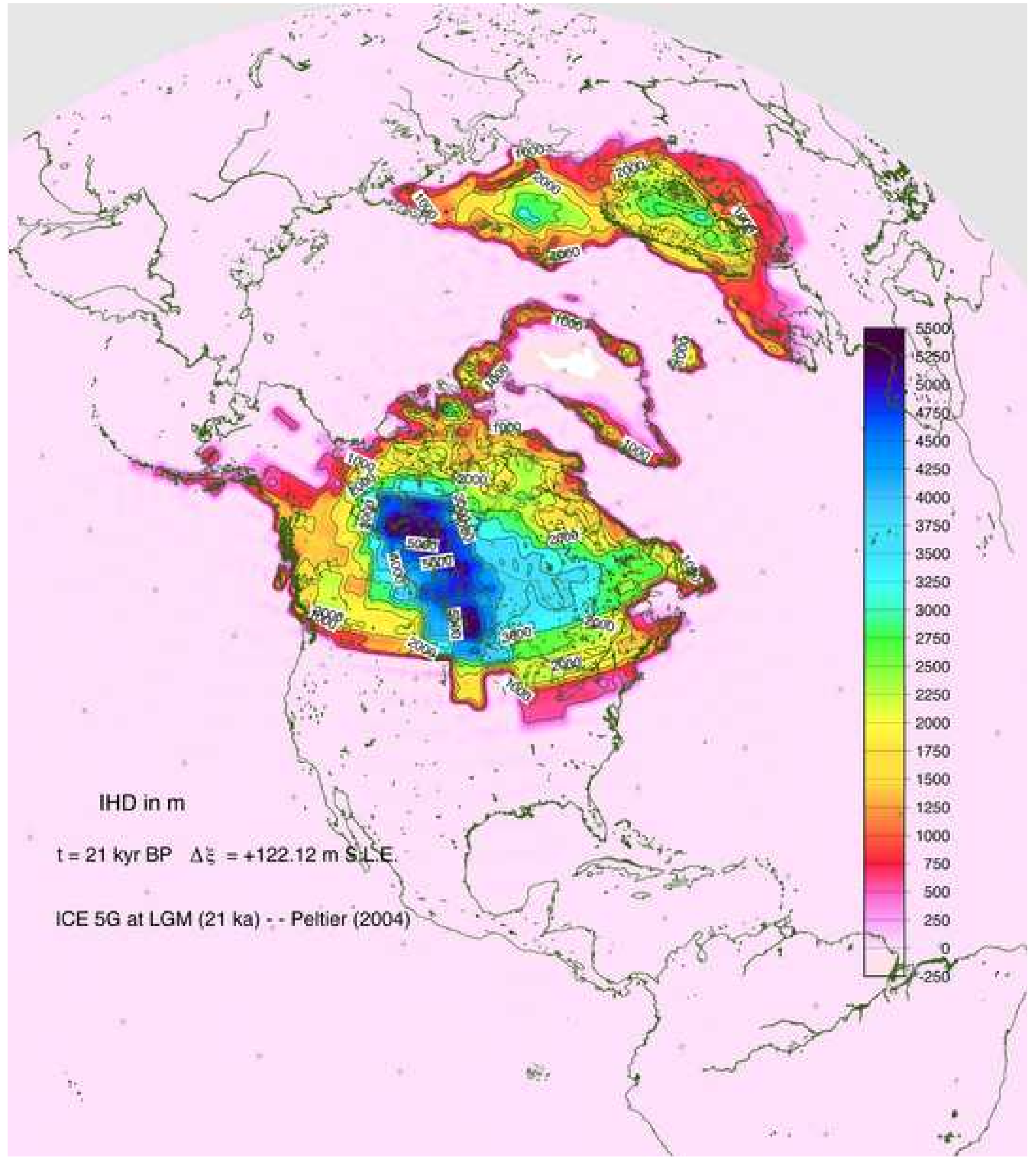

